Eur J Clin Chem Clin Biochem

1995; 33:295-305

(c) 1995 Walter de Gruyter \& Co.

Berlin · New York

\title{
Evaluation of Performance Characteristics of Automated Measurement Systems for Allergy Testing
}

\author{
By Guido M. P. J. Costongs ${ }^{1}$, Piet C. W. Janson ${ }^{1}$, Wil J. T. A. Hermans ${ }^{1}$, Rene J. M. van Oers ${ }^{2}$ and Ben Leerkes ${ }^{2}$ \\ 1 Dept. Clinical Chemistry, Maaslandziekenhuis, Sittard, The Netherlands \\ 2 Dept. Clinical Chemistry, Ziekenhuiscentrum, Apeldoorn, The Netherlands
}

(Received December 19, 1994/February 18, 1995)

\begin{abstract}
Summary: Reliability of test results, convenient handling and flexibility are major requirements on automated immunoassays systems. To investigate to what extent these requirements were met by the Pharmacia CAP and DPC IMMULITE and DPC Microplate Systems, we evaluated several performance characteristics of assays of specific IgE against some common inhalant allergens as well as the atopy tests Phadiatop (Pharmacia CAP System) and AlaTOP (DPC IMMULITE and Microplate System).
\end{abstract}

Comparing Phadiatop and AlaTOP results $(n=95)$ to clinical data, the sensitivity was found to be $97 \%$ in the Pharmacia CAP System and $82 \%$ in the AlaTOP-DPC Microplate System and $88 \%$ with AlaTOP-IMMULITE. Specificity was in all cases higher than $90 \%$.

The pooled total variation was more than twice as high with the DPC Microplate System as compared to the Pharmacia CAP System in our first investigation. A second investigation showed similar values.

The investigation of systematic differences showed that the error contribution of sample related differences between the systems was even larger and far exceeded the analytical variation. Thus the two methods do not seem to be measuring the same specific IgE antibodies. In 8 out of 8 cases with the Pharmacia CAP System positive and DPC negative results and in 2 out of 2 cases with DPC positive and Pharmacia CAP System negative results, the presence of IgE antibodies could be confirmed by IgE immunoblotting. Serum dilutions showed very irregular O/E patterns for the DPC Microplate System.

There was no effect when adding non-specific IgE to serum samples. Addition of competing IgG antibodies showed a moderate decrease in binding of specific IgE in the Pharmacia CAP System when increasing amounts of IgG were added. The effect in the DPC Microplate System was more pronounced with large decreases, or increases of measured values even at lower concentration of the competing antibody. The results may indicate insufficient allergen concentration in the DPC assay and draw attention to the risk for undesirable complex formation between allergen and antibody in solution.

The combination of the two DPC systems did not offer any advantages over Pharmacia CAP System from the handling or work flow point of view.

\section{Introduction}

Automated systems in our laboratories are expected to be easy to handle and as flexible as possible to enable laboratory personnel to work with them at all times. The recently introduced IMMULITE (DPC) $(1,2)$ which in- cludes the test AlaTOP allows random access allergy screening testing and would reduce pre analytical work time.

AlaTOP IMMULITE and follow up with allergen specific IgE tests on a DPC Microplate automated micro- 
plate system (DPC) could be an alternative to the Pharmacia CAP System presently used in one of our laboratories for differential as well as specific allergy testing in the following configuration: RoboCAP, AutoCAP and FluoroCount 96 . Studies performed previously $(3,4)$ usually compared performance to the skin prick test (SPT). In this study we wanted to examine the performance of both systems from a quantitative standpoint.

The need for initial differential tests is indicated in several studies $(5,6,7)$. The quantitative measurement of specific IgE antibodies has been proposed as a basis to correlate severity of disease with serum concentration of IgE antibodies $(8,9)$. This has also been expressed as a preference by the clinicians at and around Maaslandsziekenhuis, Sittard. The aim of the study was to investigate the performance characteristics of the tests run on the combination of two DPC systems as compared to Phadiatop and specific IgE antibody assay on the Pharmacia CAP System.

The following performance characteristics were evaluated:

- clinical sensitivity and specificity of AlaTOP in the two DPC systems and of Phadiatop ${ }^{\circledR}$

- within, between and total assay run precision

- systematic differences between the specific IgE assays

- consistency after dilution

- interference from allergen specific IgG antibodies

- influence from unspecific IgE.

Furthermore the systems were evaluated with respect to user friendliness.

\section{Materials and Methods}

Test technologies

The Pharmacia CAP System FEIA is a fluorescent enzyme immunoassay. The allergens, covalently coupled to the ImmunoCAP, react with the specific IgE in the patient serum and enzyme labelled anti-IgE antibodies are added to form a complex. This is incubated with a development agent. When the reaction is finished the fluorescence is measured.

The DPC Microplate System is an enzyme immunometric assay based on liquid ligand labelled allergens and separation by ligandcoated wells. The specific IgE in the patient sample forms an allergen-IgE complex which is incubated with a multivalent anti-ligand which in turn links the allergen-IgE complexes and the ligandcoated wells. Horseradish peroxidase labelled monoclonal anti-IgE antibodies are added to the allergen-IgE complex. A chromogenic indicator is added and the result is measured kinetically.

IMMULITE is a chemiluminescent enzyme immunoassay, based on the same principle as Microplate but utilising an alkaline phosphatase-labelled anti-human IgE which reacts with a chemiluminescent substrate. Anti ligand coated polystyrene beads are used to capture the ligand labelled allergens.

WHO-IgE based calibrators are used for determination of total IgE and values expressed in $\mathrm{kU} / \mathrm{l}$. In Pharmacia CAP System these standards are also used for the determination of specific IgE antibodies and the values are expressed in $\mathrm{kU}_{\mathrm{A}} / \mathrm{l}$. For study purposes we have used $\mathrm{kU} / \mathrm{l}$ as the measuring unit for both systems. For further details of the different test systems, see the directions for use from the system suppliers.

\section{,}

Instruments and reagents

Pharmacia CAP System instruments and reagents

RoboCAP:

AutoCAP:

FluoroCount 96:

MasterCAP:

Pharmacia CAP System

\section{$D P C$ instruments and reagents}

DPC Microplate EIA System:

MARK 5 Pipettor:

Microplate MAX Plate

Processor:

MAX software:

DPC Microplate System

IMMULITE

IMMULITE

IMMULITE

Specific IgE allergens

1d, House dust mite

el, Cat dander

e5, Dog dander

Immunoblotting

Pharmacia Diagnostics

DPC

\section{Statistical Methods}

Evaluation of precision

The standard deviations of the error components within and between runs were estimated from analysis of variance and are presented as coefficients of variation, CV(\%), i. e. the standard devia-
Pipetting of sera and allergen distribution

Incubation, reagent addition, washing and elution

Measurement of fluorescence

Patient, assay and instrument management, evaluation and report

Specific IgE and Phadiatop

Measurement of absorbance Sera and reagent pipetting Washing and incubation

Patient, assay and instrument management, evaluation and report

Specific IgE and AlaTOP

Incubation, process, reagent addition, measurement and evaluation AlaTOP allergy screen

g6, Timothy, Phleum pratense

t3, Common silver birch, Betula pendula

w6, Mugwort, Artemisia vulgaris

PAGE immunoblotting was performed essentially as described by Bengtsson et al. (10). The scanning of the IgE-antibody zones of the blot was performed with the help of Image Master ${ }^{\mathrm{TM}}$, Pharmacia Biotech, Uppsala Sweden.

Western Blot procedure was performed essentially as described by U.K. Laemmli (11). 
tion in per cent of the mean. As an estimate of a common $\mathrm{CV}$ for all species, the pooled CV is calculated according to

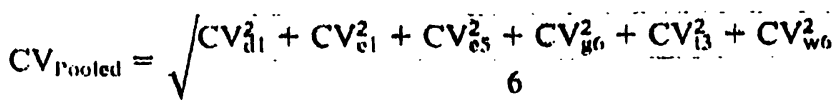

\section{Comparison of methods}

The results from the method comparison are presented graphically in $x y$-plots. Straight lines have been fitted to the $x y$-plols according to the method by Passing \& Bablok $(12-14)$. As pointed out by Altman \& Bland (15), it may be more relevant to consider the differences or ratios between the methods and therefore ratio plots, $y / x$ against $(x+y) / 2$, are also presented. By applying the statistical analysis suggested by Nilsson (16) the existence of sumple-related differences can be tested und their standard deviations estimated. To facilitate the interprotation the standard deviation of the sumplerelated differences is expressed in relation to the expected contribution to the scalter from the random variation within muns, i.c. by the quotient between the two standard deviations, in this paper denoted as the coefficients of sample-related disagrecment, CSD. This coefficient gives the relative importance between sample-related differences and the variation within runs when results from the two methods are compared. A value of CSD $>0.75$ corresponds to the rulc of thumb given in 1. c. (16) for rejection of the hypothesis of no sample-related differences (with a significance level of $5 \%$ or less). A CSD > 1.5 should be considered an indicution of a crucial contribution to a disagrecment between the incthods from sample-related differences.

As relative differences are more relevant than absolute ones, the statistical analysis is performed after logarithmic transformation of the concentrations.

\section{Experimental Design}

Estimation of clinical sensitivity and specificity of AlaTOP and Phadialop

Scrum samples from 100 consecutive pationts with suspected allorgy were used to assoss clinical sensitivity and clinical specificity. 34 werc clinically verified as atopic and 61 as non-atopic, while in 5 cases, clinical history and available in vivo test results were inconclusive. The latter were excluded from the comparison. The following alternative criteria were used for positive diagnosis of alopy: SPT of $3+$ (cqual to wheal of histamine control. $10 \mathrm{~g} / \mathrm{l}$ ), SPT $2+$ in combination with positive case history for the same allergen, SPT $1+$ or $2+$ in combinution with positive RAST for the same allergen or a positive provocation test. The critcria for a negative diagnosis of atopy was; SPT negative. SPT $1+$ in combination with negative case history or negative RAST or negative provocation test. Patients not fulfilling critoria for positive or negative atopy diagnosis were considered as inconclusive.
Age:
Sex:
Average 28 years, range $17-67$ years
Diagnosis: 60 females and 40 males
41 Bronchial asthma, 19 Scasonal rhinitis and 63 Perennial rhinitis.

The serum samples were tested with Phadiatop (Pharmacia CAP System) and AlaTOP (IMMULITE and DPC Microplate Systcm).

\section{Evaluation and compurison of performance characteristics for measurement of specilic IgE antibodies}

All assays were allocated to five runs consisting of two plates and evaluated with a scparate calibration curve and performod during a five day perjod. All sumples were coded and assayed blind.

\section{Prectsion experiment}

Allergen specific IgLi antibodics against the allergens dl, el, c5, g6, 13 and wo were assayed in one sample por allorgen in five replicales in each of the live rums.

\section{Evaluation of systematic differences}

62 patient sora per allorgen (dl, cl, e5, g6, 13 and w6) worc selected according to the results with our current routine inethod (Pharmacia CAP System) and used to assess the possible concordance between DPC Microplate system spocific IgE Microplate (DPC Microplatc System) and RAST (Pharmacia CAP Systcm).

\section{Dilution experiments}

Two patient sera for each of the allergens dl, cl, c5, g6, 13 and w6 wore diluted and assayed in duplicate, undiluted and diluted with negative serum to $1: 2,1: 4,1: 8$ and $1: 16$. The diluent consisted of pooled human surum from healthy controls, presenting responses below $50 \%$ of the cul-off in both systems and a concentration of total lgE of approximately $5 \mathrm{kU} / \mathrm{l}$. Al dilutions were made independently from the origin sample. All assays were allocated to the same run. The $100 \mathrm{kU} / \mathrm{l}$ calibrator was also diluled and assayed in the same way for the two sysicms, respectively.

\section{Addition experiment: $\lg E$}

One negative control serum per allergen (dl, el, e5, g6, t3 and w6) and method was spiked with myeloma lgE to total lgE levels of approximately 1000 and $3000(\mathrm{kU} / \mathrm{l})$ units to test for unspecificd binding of IgE protein. All samples were assayed in duplicalc in the same run.

\section{Addition experiment: Allergen specific $\lg G$ antihodies}

Allergen specific rabbit antisera were diluted with normal rabbit scrum to $1: 2,1: 4$ and $1: 8$. One patient serum for each of the allergens $d 1, g 6$ and $t 3$ was mixed in equal parls with negative human serum, normal rabbit serum, the undiluted and the three dilutions of the anti sera. Thus a series of six samples with the same proportion of the patient serum is obtained. One is diluted by human negative serum and the other five contain the $\operatorname{lgG}$ antibodies (rabbit antiserum) in the proportions $1: 2,1: 4,1: 8,1: 16$ and 0 . All six samples for each allorgen were assayed in duplicale in the sume run. This experiment shows relative dilferences in risk for interference by non-lgE antibodies competing for the sanne allergen and may be considered as a test of the capacity of the allergen reagent.

\section{Comparison of calibrators}

The assigned values of the calibrators were checked for both systoms by assaying the DPC Microplate System calibrators in duplicate in the Pharmacia CAP System and vice versa.

\section{Results and Discussion}

Clinical performance of Phadiatop and AlaTOP

The results for Phadiotop (Pharmacia CAP System) and AlaTOP (IMMULITE and DPC Microplate System) are 
Tab. 1 Clinical sensitivity and specificity for Phadiatop and AlaTOP.

\begin{tabular}{|c|c|c|c|c|c|c|c|}
\hline \multirow[t]{2}{*}{ Diagnosis } & \multirow[t]{2}{*}{$\begin{array}{l}\text { Num- } \\
\text { ber }\end{array}$} & \multicolumn{2}{|c|}{$\begin{array}{l}\text { Phadia- } \\
\text { top }\end{array}$} & \multicolumn{2}{|c|}{$\begin{array}{l}\text { AlaTOP } \\
\text { IMMU- } \\
\text { LITE }\end{array}$} & \multicolumn{2}{|c|}{$\begin{array}{l}\text { AlaTOP } \\
\text { Micro- } \\
\text { plate }\end{array}$} \\
\hline & & pos & neg & pos & neg & pos & neg \\
\hline $\begin{array}{l}\text { Atopic } \\
\text { Non-atopic }\end{array}$ & $\begin{array}{l}34 \\
61\end{array}$ & $\begin{array}{r}33 \\
4\end{array}$ & $\begin{array}{r}1 \\
57\end{array}$ & $\begin{array}{r}30 \\
0\end{array}$ & $\begin{array}{r}4 \\
61\end{array}$ & $\begin{array}{r}28 \\
4\end{array}$ & $\begin{array}{r}6 \\
57\end{array}$ \\
\hline $\begin{array}{l}\text { Sensitivity } \\
(\%)\end{array}$ & & \multicolumn{2}{|c|}{97} & \multicolumn{2}{|c|}{88} & \multicolumn{2}{|c|}{82} \\
\hline $\begin{array}{l}\text { Specificity } \\
(\%)\end{array}$ & & \multicolumn{2}{|c|}{93} & \multicolumn{2}{|c|}{100} & \multicolumn{2}{|c|}{93} \\
\hline
\end{tabular}

given in table 1 together with estimates of clinical sensitivity and specificity.

33 out of 34 sera $(97 \%)$ of the atopic patients were correctly classified as positive by Phadiatop. The corresponding figures for AlaTOP were 30 out 34 for IMMULITE and 28 out of 34 for DPC Microplate System. Specificity varied from $93-100 \%$. These findings corre- late well with results reported in other studies (17-19). A differential diagnostic test for atopy is often the first test to be performed on a patient and is followed by allergen specific testing in the cases considered atopic i. e. in those cases with positive Phadiatop/AlaTOP. It is obvious that high sensitivity is essential in this situation.

\section{Technical performance of specific IgE test systems \\ Precision}

The random variation expressed as total $\mathrm{CV}$ as well as the variation within and between runs for the DPC Microplate System were more than twice as high as for the Pharmacia CAP System (see tab. 2, trial 1). The obtained results $(\mathrm{kU} / \mathrm{l})$ in trial 1 were also higher with the Pharmacia CAP System than with the DPC Microplate System, apart from $\mathrm{g} 6$ where the figure was obtained by extrapolation by the DPC software.

In order to rule out a faulty instrument as the cause of imprecision (tab. 2, trial 4 only DPC) and to compare the precision in the lower part of the measuring range
Tab. 2 Results from first (trial 1) and second (trial 2 \& 3) precision experiment. Mean concentrations from 5 runs are given in $\mathrm{kU} / \mathrm{h}$ except trial 1 with DPC which is based on 10 runs. Coeffi- cients of variation, $\mathrm{CV}$, are given in $\%{ }^{*}=$ Value obtained by extrapolation

\begin{tabular}{|c|c|c|c|c|c|c|c|c|}
\hline \multirow[t]{2}{*}{ Allergen } & \multirow[t]{2}{*}{ Estimate } & \multicolumn{3}{|c|}{ Pharmacia CAP System } & \multicolumn{4}{|c|}{ DPC Microplate System } \\
\hline & & trial 1 & trial 2 & trial 3 & trial 1 & trial 2 & trial 3 & trial 4 \\
\hline $\mathrm{dl}$ & $\begin{array}{l}\text { Mean conc. kU/1 } \\
\text { Between run CV (\%) } \\
\text { Within run CV (\%) } \\
\text { Total CV (\%) }\end{array}$ & $\begin{array}{r}10.1 \\
7.5 \\
6.3 \\
9.8\end{array}$ & $\begin{array}{r}0.58 \\
7.2 \\
9.4 \\
11.8\end{array}$ & $\begin{array}{l}1.70 \\
5.3 \\
9.2 \\
10.6\end{array}$ & $\begin{array}{r}5.2 \\
17.6 \\
17.3 \\
24.7\end{array}$ & $\begin{array}{l}0.36 \\
10.4 \\
12.5 \\
16.2\end{array}$ & $\begin{array}{l}1.20 \\
8.6 \\
15.5 \\
17.7\end{array}$ & $\begin{array}{l}38.7 \\
19.3 \\
31.3 \\
35.9\end{array}$ \\
\hline el & $\begin{array}{l}\text { Mean conc. kU/l } \\
\text { Between run CV (\%) } \\
\text { Within run CV }(\%) \\
\text { Total CV }(\%)\end{array}$ & $\begin{array}{r}23.5 \\
6.5 \\
9.8 \\
11.6\end{array}$ & $\begin{array}{l}0.63 \\
6.3 \\
16.0 \\
17.2\end{array}$ & $\begin{array}{l}2.25 \\
6.0 \\
6.2 \\
8.6\end{array}$ & $\begin{array}{l}15.4 \\
10.8 \\
12.3 \\
16.3\end{array}$ & $\begin{array}{c}1.70 \\
9.0 \\
10.9 \\
14.1\end{array}$ & $\begin{array}{l}3.23 \\
7.0 \\
10.5 \\
12.6\end{array}$ & $\begin{array}{r}6.3 \\
6.8 \\
9.0 \\
11.3\end{array}$ \\
\hline e5 & $\begin{array}{l}\text { Mean conc. kU/1 } \\
\text { Between-run CV (\%) } \\
\text { Within run CV (\%) } \\
\text { Total CV }(\%)\end{array}$ & $\begin{array}{r}27.8 \\
6.3 \\
7.5 \\
9.8\end{array}$ & $\begin{array}{l}0.44 \\
9.0 \\
8.7 \\
12.5\end{array}$ & $\begin{array}{l}2.28 \\
5.5 \\
8.0 \\
9.7\end{array}$ & $\begin{array}{l}27.3 \\
16.5 \\
30.0 \\
34.2\end{array}$ & $\begin{array}{l}0.37 \\
5.5 \\
14.0 \\
15.0\end{array}$ & $\begin{array}{l}1.85 \\
9.4 \\
14.5 \\
17.2\end{array}$ & $\begin{array}{l}94.5 \\
13.4 \\
43.9 \\
45.8\end{array}$ \\
\hline g6 & $\begin{array}{l}\text { Mean conc. kU/I } \\
\text { Between run CV (\%) } \\
\text { Within run CV }(\%) \\
\text { Total CV }(\%)\end{array}$ & $\begin{array}{r}72.1 \\
4.8 \\
12.1 \\
13.0\end{array}$ & $\begin{array}{l}0.45 \\
6.8 \\
7.3 \\
10.0\end{array}$ & $\begin{array}{l}2.16 \\
5.1 \\
6.8 \\
8.5\end{array}$ & $\begin{array}{l}228.8^{*} \\
24.2 \\
22.1 \\
32.8\end{array}$ & $\begin{array}{l}0.096^{*} \\
10.4 \\
9.4 \\
14.1\end{array}$ & $\begin{array}{l}1.76 \\
8.8 \\
11.6 \\
14.6\end{array}$ & $\begin{array}{l}14.1 \\
1.76 \\
7.29 \\
7.50\end{array}$ \\
\hline $\mathrm{t} 3$ & $\begin{array}{l}\text { Mean conc. kU/1 } \\
\text { Between run CV (\%) } \\
\text { Within run CV }(\%) \\
\text { Total CV }(\%)\end{array}$ & $\begin{array}{l}9.6 \\
5.9 \\
4.3 \\
7.3\end{array}$ & $\begin{array}{l}0.57 \\
9.5 \\
7.5 \\
12.2\end{array}$ & $\begin{array}{l}1.39 \\
4.8 \\
7.6 \\
8.9\end{array}$ & $\begin{array}{r}6.0 \\
14.4 \\
16.4 \\
21.9\end{array}$ & $\begin{array}{l}0.37 \\
5.5 \\
14.0 \\
15.0\end{array}$ & $\begin{array}{r}1.85 \\
9.4 \\
14.5 \\
17.2\end{array}$ & $\begin{array}{l}35.7 \\
11.3 \\
20.3 \\
23.2\end{array}$ \\
\hline w6 & $\begin{array}{l}\text { Mean conc. kU/1 } \\
\text { Between run CV (\%) } \\
\text { Within run CV }(\%) \\
\text { Total CV }(\%)\end{array}$ & $\begin{array}{l}7.7 \\
5.3 \\
6.1 \\
8.1\end{array}$ & $\begin{array}{l}0.53 \\
5.8 \\
7.7 \\
9.6\end{array}$ & $\begin{array}{l}- \\
- \\
-\end{array}$ & $\begin{array}{r}1.8 \\
9.4 \\
19.6 \\
21.8\end{array}$ & $\begin{array}{l}0.92 \\
16.7 \\
12.7 \\
21.0\end{array}$ & $\begin{array}{l}- \\
- \\
-\end{array}$ & $\begin{array}{l}0.25^{*} \\
7.4 \\
15.1 \\
16.9\end{array}$ \\
\hline Pooled CV & $\begin{array}{l}\text { Between run CV (\%) } \\
\text { Within run CV }(\%) \\
\text { Total CV }(\%)\end{array}$ & $\begin{array}{r}6.1 \\
8.1 \\
10.2\end{array}$ & $\begin{array}{l}- \\
- \\
-\end{array}$ & $\begin{array}{l}- \\
- \\
-\end{array}$ & $\begin{array}{l}16.2 \\
20.4 \\
26.1\end{array}$ & $\begin{array}{l}- \\
-\end{array}$ & $\begin{array}{l}- \\
-\end{array}$ & $\begin{array}{l}- \\
-\end{array}$ \\
\hline
\end{tabular}


(tab. 2, trial 2,3) a second investigation was performed with the Pharmacia CAP System and manually (without Mark V pipette) with the DPC System. This showed a similar relation between the systems in terms of coefficient of variation as in trial 1 . In trial two, three and four, new sets of sera were used, so no correlation between the trials was possible.

The Mark V instrument might contribute to a general increase of the imprecision, but random variation of the size shown by the DPC Microplate System makes testing with single determinations questionable.

\section{Systematic differences}

The calibrator range for both methods is $0.35-100 \mathrm{kU} / \mathrm{l}$. The distribution of results below, within and above the measurement range with the two methods is given in table 3.

A high number of samples, between $4 \%$ and $16 \%$ for the different species, were reported as above the highest standard point in the DPC Microplate System. The reason for this can not be deducted from this experiment but the high variation, the unpredictable behaviour of serum samples and the calibrator in the dilution experiments and the need for individual optimisation of the allergen reagents are probably major contributing factors.

A first comparison between methods was performed on a class basis and showed the agreement between nega-

Tab. 3 Distribution of results below, within and above the calibrator range $(0.35-100 \mathrm{kU} / \mathrm{l})$. Shadowed boxes show discrepancies between the systems.

\begin{tabular}{llrrr}
\hline \multirow{2}{*}{ Allergens } & Pharmacia & \multicolumn{2}{c}{ DPC Microplate } \\
\cline { 3 - 5 } & CAP & Below & Within & Above \\
\hline \multirow{2}{*}{ System } & Below & 32 & 0 & 0 \\
& Within & 5 & 22 & 3 \\
& Above & 0 & 0 & 0 \\
el & Below & 31 & 1 & 0 \\
& Within & 2 & 22 & 5 \\
& Above & 0 & 1 & 0 \\
e5 & Below & 31 & 0 & 0 \\
& Within & 0 & 24 & 7 \\
& Above & 0 & 0 & 0 \\
g6 & Below & 31 & 1 & 0 \\
& Within & 3 & 19 & 7 \\
& Above & 0 & 0 & 1 \\
t3 & Below & 29 & 1 & 0 \\
& Within & 0 & 22 & 10 \\
& Above & 0 & 0 & 0 \\
& Below & 31 & 1 & 0 \\
w6 & Within & 2 & 25 & 3 \\
& Above & 0 & 0 & 0 \\
& & & &
\end{tabular}

tive samples. $7 \%$ (12 out of 197) of the samples were positive in the Pharmacia CAP System and negative in the DPC Microplate System. Out of the positive samples $(n=155)$, we observed that $45 \%$ were within the same class. $34 \%$ of the positive samples in DPC were within \pm 1 class of Pharmacia values, $19 \%$ of the positive sample in DPC within \pm 2 classes of Pharmacia values and $2 \%$ deviated more than 2 classes from the Pharmacia value. A connected observation was that the DPC Microplate System gave lower values than Pharmacia in the low range and higher values in the high range. This means that of those results matching $(n=75), 72$ results were found within class $2-4$.

Cases with discrepant results in the low range (tab. 3 and fig. 1), i.e. measurable with the Pharmacia CAP System but not with the DPC Microplate System and vice versa, were further studied by immunoblotting.

The twelve samples which were Pharmacia positive and DPC negative had specific IgE values in the range of $0.75-12.1 \mathrm{kU} / 1$, eight of these were still available and sent to Pharmacia Diagnostics for analysis. In seven of eight cases presence of allergen specific antibodies could be demonstrated and optical density of blotting pattern scanned, see figure 1 . The IgE antibodies were found to represent major as well as minor allergenic components of house dust mite, cat dander, timothy pollen and mugwort pollen (Pharmacia, personal communication). In the remaining case, serum no. 80 , not present in figure 1 , very week staining corresponding to the major mugwort allergens could be seen but not recorded because of limitations of sensitivity in the scanning equipment. All the cases with positive Pharmacia CAP System readings were confirmed by the analysis of $\mathrm{IgE}$ antibodies against individual allergenic components.

Two sera, no. 174 and no. 267, resulted in DPC positive and Pharmacia negative results. IgE antibodies detectable in the Western blot procedure were reported for timothy pollen, birch pollen, mugwort pollen and cat epithelia. No immunoblotting figures were included in the communication (DPC, personal communication).

\section{Quantitative evaluation of systematic differences}

For investigation of quantitative agreement between the methods both plots of $y$ (DPC) versus $x$ (Pharmacia) and of $y / x$ (on a logarithmic scale) versus $(x+y) / 2$ are given in figure 2 . The estimated straight lines and coefficients of correlation for the xy-plots according to Passing \& Bablock are given in table 4. Overall there is a low correlation between the methods. In order to examine the disagreement between the methods the suggestions put forward by Nilsson (16) were followed. Only samples with both results within the calibrator range 


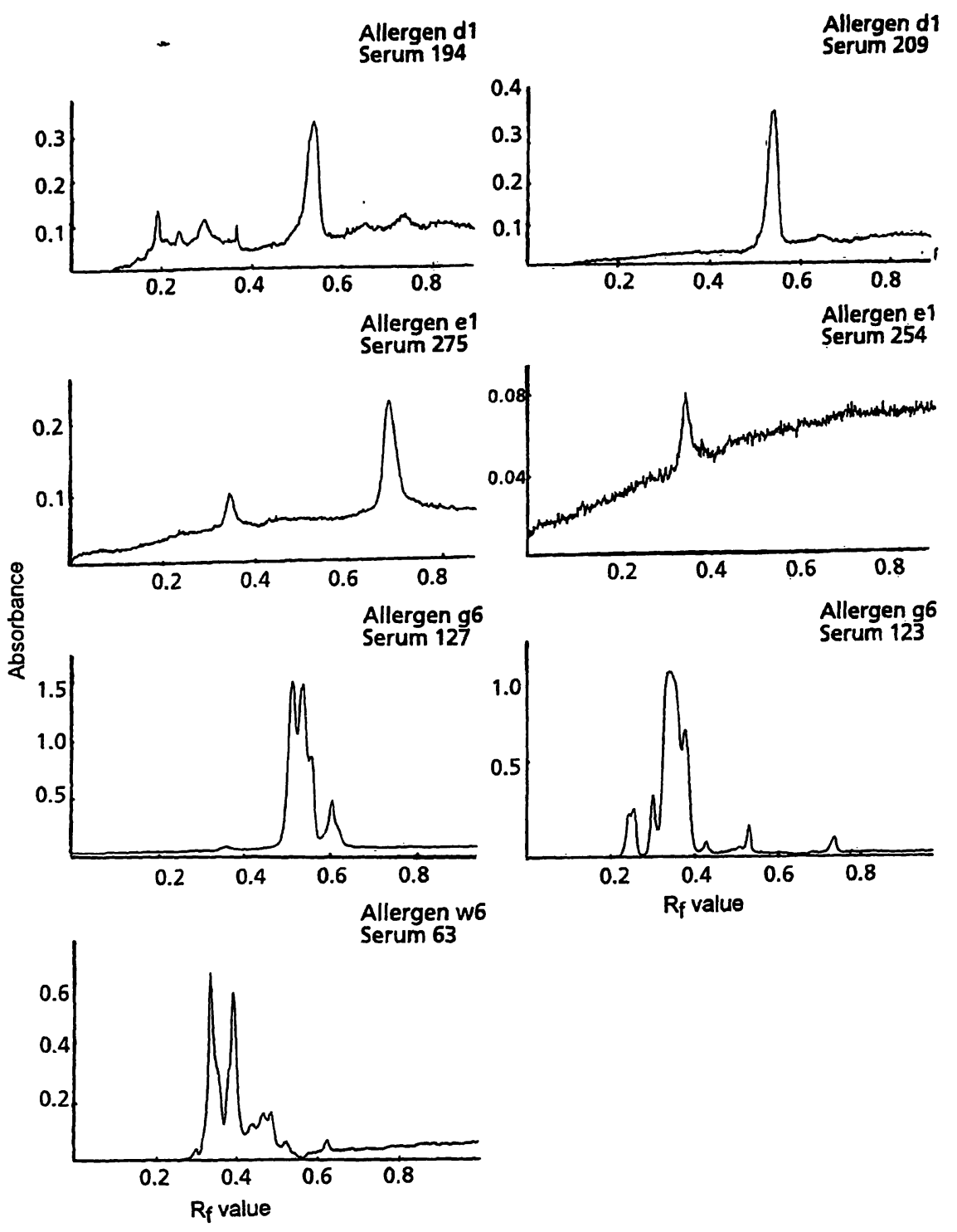

Fig. 1 Detection of allergen specific IgE antibodies by immunoblotting with pollen (timothy (Phleum pratense) and mugwort

(Arthemisia vulgaris)), house dust mite, cat dander in serum samples with discordant test results. (Pharmacia+/DPC -)

were included. From the precision experiment, with g6 excluded for the DPC Microplate System (above range), the expected standard deviation of the scatter expressed in In (concentration) was estimated as 0.22 . No indication of dependence between differences and concentration level was obtained and the mean difference expressed in per cent of the result with the Pharmacia CAP System was calculated. These values and the CSD-values (the coefficient of sample-related disagreement) are given in table 5 . For all allergens the sample-related differences are șignificant and as can be seen in table 5 the CSD-values are substantially greater than 1.5. This indicates that the error contribution from sample-related differences far exceeds the analytical variation presented in table 2.

Although an xy-plot may indicate a correlation between the methods, a ratio plot shows that the disagreement is considerable. From the ratio plot for $\mathrm{d} 1$ for example, it is evident that the ratio $\mathrm{y} / \mathrm{x}$ varies between 10 and $300 \%$.
The sample-related differences are probably caused by different capabilities of the two test systems to measure individual mixtures of IgE antibodies against the allergenic components of an allergen. Furthermore, as the observed mean differences of the DPC Microplate System vary between $-25 \%$ for $\mathrm{g} 6$ and $+110 \%$ for $\mathrm{e} 5$, differences between the allergens also in terms of calibration can hardly be excluded. On the contrary, it is very likely that a variable calibration error is introduced in a system where each individual allergen-reagent lot must be adjusted to an optimal signal level (DPC) rather than to allergen excess (Pharmacia).

It is obvious from the study of systematic differences that several samples with clearly measurable levels of IgE antibodies remain undetected by the DPC Microplate System. This fact and the observation that many cases with low to moderate levels show lower levels with DPC, is in concordance with the sample related differences between methods discussed above. Insuffi- 


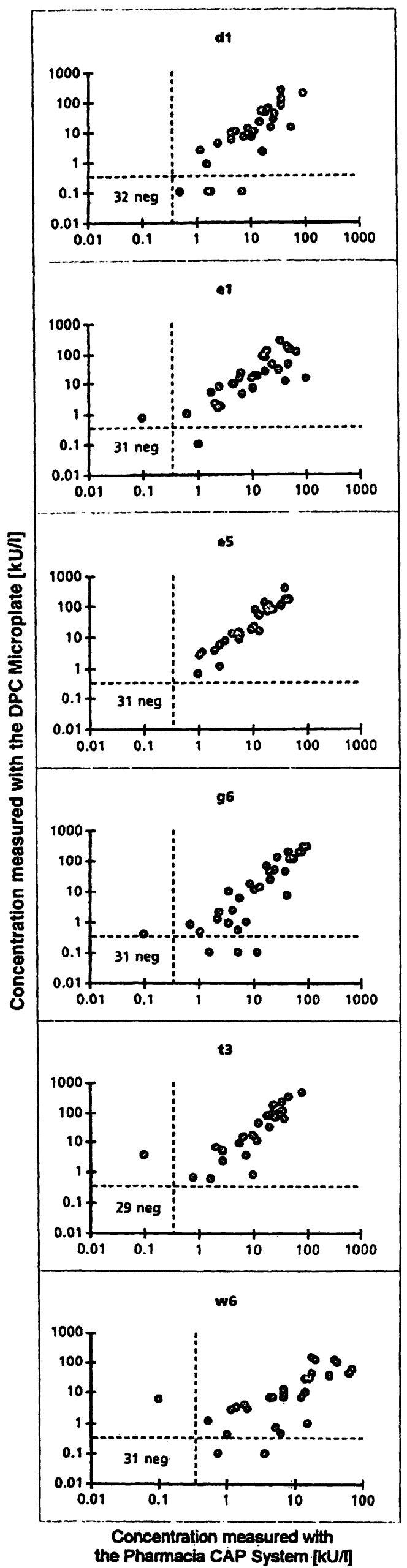

Fig. 2 Concentration with DPC Microplate System (y) is plotted against concentration with Pharmacia CAP System $(x)$ in the dia-

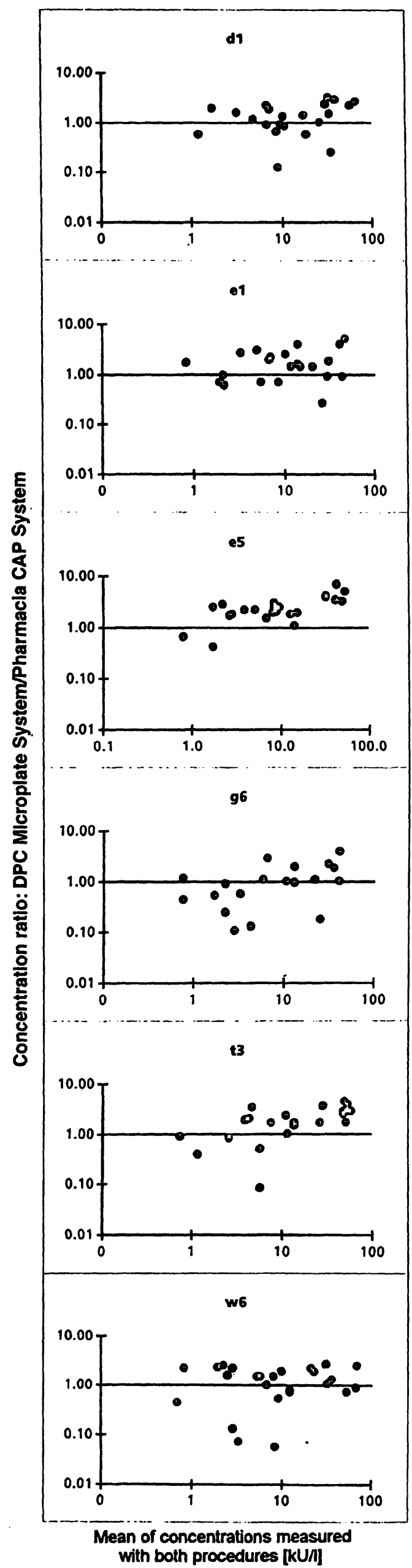

grams to the left. For results within the measurement range to ratio $y / x$ is plotted against $(x+y) / 2$ in the diagrams to the right. 
Tab. 4 Method comparison according.to Passing \& Bablok

\begin{tabular}{lllll}
\hline Allergen & $n$ & Slope & Intercept & $\begin{array}{l}\text { Coefficient of } \\
\text { correlation } \mathrm{r}\end{array}$ \\
\hline $\mathrm{dl}$ & 26 & 1.849 & -3.089 & 0.655 \\
$\mathrm{el}$ & 24 & 1.559 & -1.421 & 0.516 \\
$\mathrm{e} 5$ & 23 & 3.512 & -4.630 & 0.876 \\
$\mathrm{~g} 6$ & 22 & 1.200 & -2.076 & 0.595 \\
$\mathrm{t} 3$ & 20 & 2.906 & -6.257 & 0.877 \\
$\mathrm{w} 6$ & 27 & 1.256 & 0.426 & 0.809 \\
\hline
\end{tabular}

Tab. 5 Comparison of systematic differences. The mean differences are expressed in per cent of the results with Pharmacia CAP System. CSD is the quotient between the standard deviation of sample-related differences and the standard deviation from the total within run variation.

\begin{tabular}{llcl}
\hline Allergen & No. of sera & Mean difference \% & CSD \\
\hline d1 & 22 & 11 & 3.23 \\
el & 22 & 39 & 3.14 \\
e5 & 24 & 110 & 2.05 \\
g6 & 19 & -25 & 3.82 \\
t3 & 22 & 51 & 3.32 \\
w6 & 25 & -6 & 4.09 \\
\hline
\end{tabular}

cient excess of allergen and/or missing allergenic components in the DPC system reagents are the most probable causes for such a deviation.

\section{Effect of dilution}

The ratios between observed $(O)$ and expected $(E)$ values for all diluted samples were calculated. Plots of $\mathrm{O} / \mathrm{E}$ against dilution give a rather regular pattern for the Pharmacia CAP System while the DPC Microplate System exhibits more dramatic effects and very irregular patterns as illustrated in figure 3 . Due to the irregular pattern shown by DPC it is not relevant to fit a model to the relationship between $\mathrm{O} / \mathrm{E}$ and dilution and the results can hardly be summarized numerically in any meaningful way. Dilution of the calibrator $100 \mathrm{kU} / \mathrm{l}$ also showed an irregular pattern, which was confirmed in a repeated experiment. The unpredictable result may, according to the manufacturer, be an effect of interference by auto-anti-IgE, affinity dependent variation in a nonexcess situation or an under representation of rare allergenic proteins in the allergen reagent.

\section{Effect of addition of unspecific IgE}

All values are below the measuring range, i. e. $<0.35$ $\mathrm{kU} / \mathrm{l}$. Thus, addition of unspecific IgE up to $3000 \mathrm{kU} / \mathrm{l}$ does not interfere with specific IgE measurements in the systems under study.

\section{Effect of addition of competing IgG antibodies}

The values obtained for sera mixed with negative rabbit serum are referred to as expected values $(E)$ and the observations of all other mixtures (O) are expressed as $\mathrm{O} / \mathrm{E}$. The mixtures with negative patient serum are used to check whether dilutions with negative patient and rabbit serum respectively can be considered as equivalent. The obtained values of O/E for these mixtures are in the range $86-107 \%$ for Pharmacia and $85-120 \%$ for DPC, i. e. well within the range of random variation. For the mixtures with rabbit serum $\mathrm{O} / \mathrm{E}$-values are plotted against percent of rabbit IgG serum in the sample. As can be seen from figure 4, the Pharmacia CAP System gives a moderate decrease for increasing amounts of rabbit IgG while the effects in the DPC Microplate System are varying and more dramatic. The results may be explained by the fact that liquid allergens can be aggregated by allergen specific IgG antibodies present in the serum sample (Personal communication, PDC). the data also support the observations made in the evaluation of systematic differences suggesting insufficient allergen excess in the DPC system.

\section{Comparison of calibrators}

The results of the DPC calibrators assayed in the Pharmacia CAP System and the Pharmacia calibrators assayed in the DPC Microplate System are shown in table 6. The table shows the observed concentrations in percent of the assigned (expected) concentrations.

The calibrators are in good agreement, and the diverging results obtained when measuring with the DPC Microplate System are in accordance with the high variation seen in the precision study.

\section{User friendliness}

The instruments included with the Pharmacia CAP System are MasterCAP, RoboCAP, AutoCAP and Fluorocounter 96. The DPC Microplate System includes MARK 5 Robotic Pipettor, MAX Automated Plate Processor with a built-in kinetic reader and a computer with MAX software designed for DPC Microplate System.

These two systems are similar in function and do not deviate much from a handling point of view, however, the limitations in DPC MARK V, such as the restriction to 4 replicates per patient and the limitation of 96 samples per assay make RoboCAP, where no such limitations exist, a preferable alternative.

One factor we consider negative is the handling of allergens in DPC Microplate System. The allergens supplied in a bottle have to be opened and closed in combination 


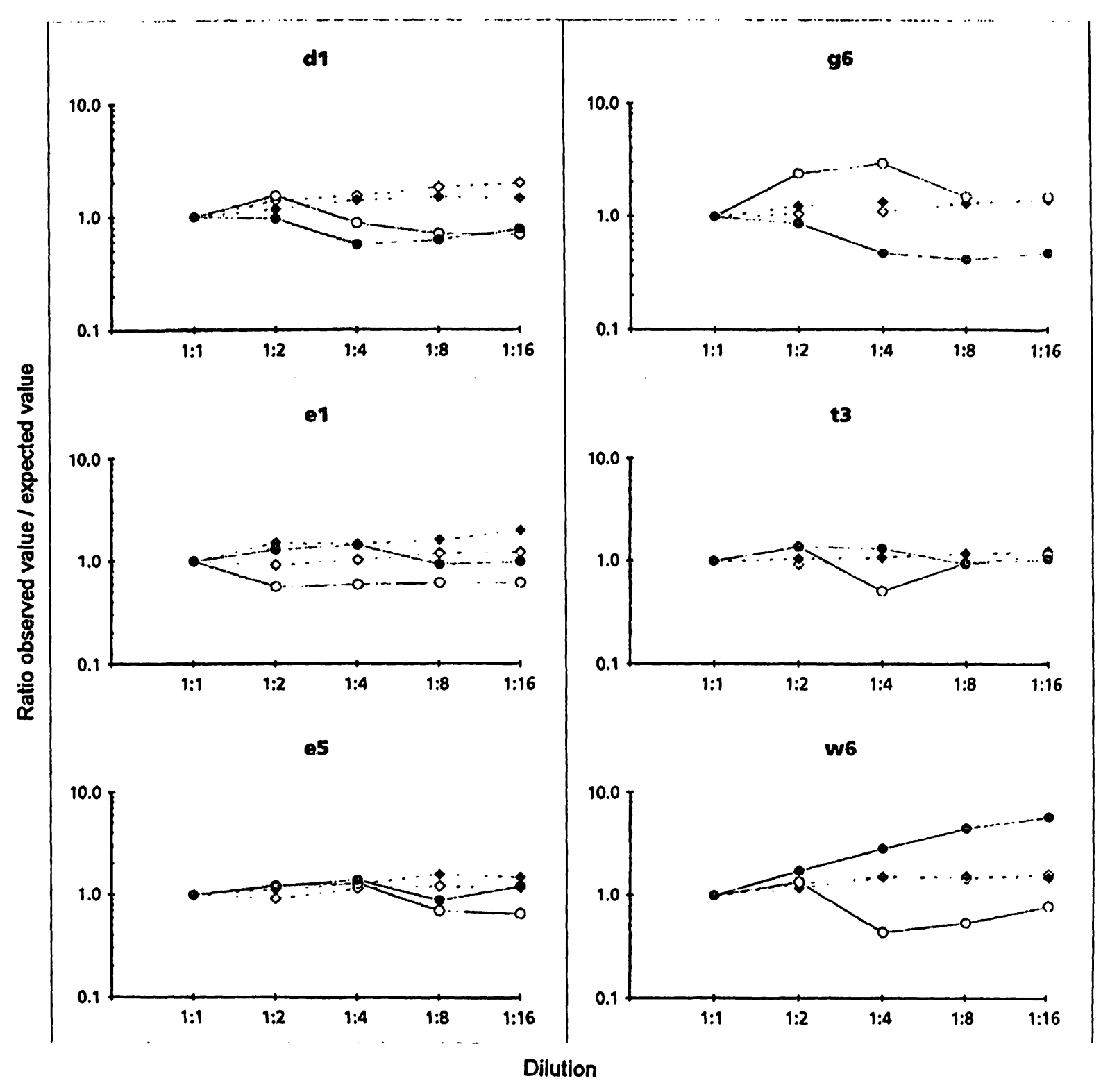

Fig. 3 Results from dilutions of two scra ( 1 and 2) for each allergen with the Pharmacia CAP System (Ph) and the DPC Microplate System (DPC). $\mathrm{O} / \mathrm{E}$ plotted against dilution.

$\begin{array}{ll}- & \text { PH : } 1 \\ ---\diamond-\infty- & \text { PH: } 2\end{array}$

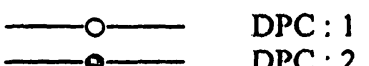

with each assay, a tedious procedure for a large panel of allergens.

For DPC IMMULITE, the first results were obtained after $1 \mathrm{~h} 15$ minutes, the time for 50 results was $2 \mathrm{~h} 7$ minutes. This shows a theoretical time advantage when using the system for differential testing but in practice no advantage in using the DPC IMMULITE AlaTOP for allergy screening instead of the Pharmacia CAP System Phadiatop was found.

RoboCAP is the more flexible and casier to operate instrument when comparing the two systems or systcm combinations, Pharmacia CAP System to DPC Microplate System and IMMULITE, we find Pharmacia CAP

System to be easier to handle as well as to adapt to sample and information flow in our laboratory.

\section{Conclusions}

We found no advantages to the combination of two DPC systems from a handling and work flow point of view. Morcover the Pharmacia CAP System is easier to work with than the DPC Microplate System. Comparing Phadiatop and AlaTOP and investigating the specific IgE antibody assays and their capability to meet our quality demands and the need of quantitative measurement expressed by clinicians, we conclude the following: 
Phadiatop has a slightly higher sensitivity than AlaTOP either on IMMULITE or on DPPC Microplate System. Both tests perform as expected from the literature $(5-7)$. But from a screening point of view high sensitivity is preferential.

d1
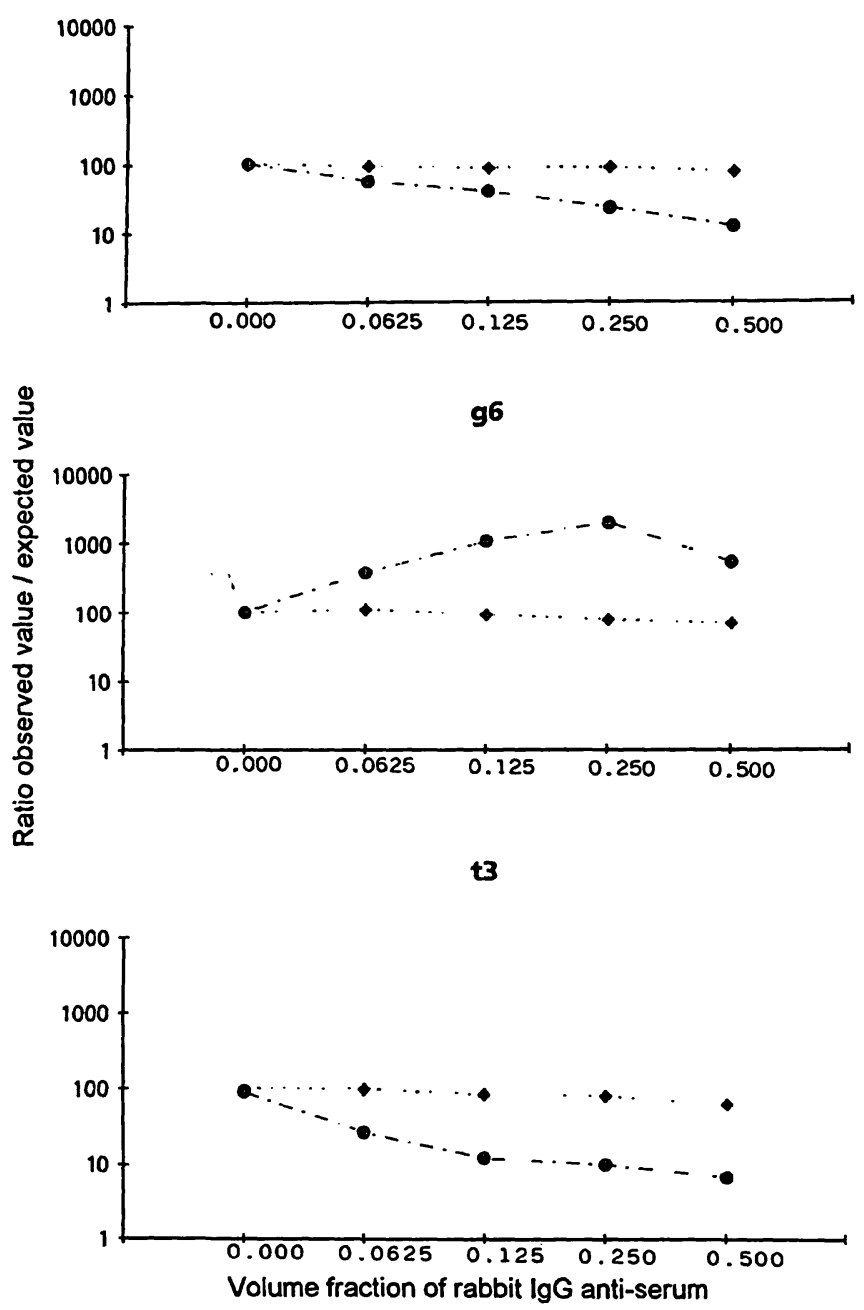

Fig. 4 Effect of increasing amount of rabbit IgG antibodies on the determination of specific IgE against $d \mathrm{l}, \mathrm{g} 6$ and $\mathrm{t} 3$.

$\cdots \cdots \cdots$ Pharmacia CAP System

-..-. D DPC Microplate System.
The DPC Microplate System was shown to be less accurate when compared with the Pharmacia CAP System. This is true for moderate and higher concentrations, where we found 2.5 times higher CV's. But at concentrations below $3.5 \mathrm{kU} / 1$ the DPC Microplate System shows, in general, higher CV's. The comparison of results show that the two methods do not, to the full extent, measure the same antibodies. This can be concluded based on the results of the correlation/regression (Passing, Bablok) but more clearly based the study of the sample related disagreement (CSD).

Furthermore DPC failed to detect specific $\operatorname{IgE}$ in at least 12 out of 187 patient samples which were in 8 cases found positive with Pharmacia CAP System and confirmed with blotting experiments. In contrary only 2 samples that were positive by DPC Microplate System and confirmed by blotting were found negative in Pharmacia CAP System. 35 results out of the 187 patient samples were above the calibrator range in the DPC Microplate System. The corresponding figure for the Pharmacia CAP System was 1 result.

There was no effect when adding non-specific IgE to serum samples and the comparison of calibrators show a good agreement. When looking at the addition of competing IgG antibodies we demonstrated a moderate decrease in binding of specific IgE in Pharmacia CAP System.

The effect in the DPC Microplate System was more pronounced with large decreases or increases of measured values even at lower concentrations. The results may indicate insufficient allergen concentration in the DPC assay and draw attention to the risk for undesirable complex formation between allergen and antibody in solution.

Finally we conclude that the Pharmacia CAP System provides quantitative measurement of allergen specific IgE antibodies with acceptable analytical variation (Pooled CV $\approx 10 \%$ ), whereas the DPC Microplate Sys-

Tab. 6 Observed concentrations of calibrators in percent of the assigned concentrations.

$*=$ value obtained by extrapolation.

\begin{tabular}{|c|c|c|c|c|c|}
\hline \multicolumn{2}{|c|}{$\begin{array}{l}\text { DPC calibrators } \\
\text { assayed in Pharmacia CAP System } \\
\text { Concentration (kU/l) }\end{array}$} & \multirow[t]{2}{*}{$\begin{array}{l}\mathrm{O} / \mathrm{E} \times 100 \\
(\%)\end{array}$} & \multicolumn{2}{|c|}{$\begin{array}{l}\text { Pharmacia calibrators } \\
\text { assayed in DPC Microplate System } \\
\text { Concentration (kU/l) }\end{array}$} & \multirow[t]{2}{*}{$\underset{(\%)}{\mathrm{O} / \mathrm{E}} \times 100$} \\
\hline Assigned & Observed & & Assigned & Observed & \\
\hline 0.35 & Below range & - & 0.35 & $0.33 * *$ & 93 \\
\hline 0.7 & 0.79 & 112 & 0.7 & 0.70 & 100 \\
\hline 3.5 & 3.49 & 100 & 3.5 & 4.04 & 115 \\
\hline 17.5 & 17.8 & 101 & 17.5 & 17.9 & 102 \\
\hline 52.5 & 50.2 & 96 & 50 & 61.9 & 124 \\
\hline 100 & Above range & - & 100 & 94.6 & 95 \\
\hline
\end{tabular}


tem results in higher variation and unwanted side effects when diluting and interfering with IgG. There also seem to be some problems with stability of the specific IgE test. The data obtained in this study support the statement that allergen excess is needed for accurate mea- surement of $\operatorname{IgE}$ antibodies. Even though the reagent prices are marginally higher, we prefer the Pharmacia CAP System for differential as well as specific IgE testing.

\section{References}

1. Babson AL. The cirrus IMMULITE ${ }^{\mathrm{TM}}$ automated immunoassay system. J Clin Immunoassay 1991; 14:83-8.

2. Babson AL, Olson DR, Palmieri T, Ross AF, Becker DM, Mulqueen PJ. The IMMULITE assay tube: a new approach to heterogeneous ligand assay. Clin Chem 1991; 37:1521-2.

3. van Houte AJ, Bartels PCM. Comparative evaluation of the Pharmacia CAP system and the DPC AlaSTAT system for in vitro detection of allergen-specific IgE with the skin prick test. Eur J Clin Chem Clin Biochem 1992; 30:101-5.

4. Ito K, Miyamato T, Makino S, Fukuda T, Kushima A, Kobayashi $S$ et al. Usefulness of AlaSTAT, a new method for the measurement of IgE. Arerugi 1991; 40:44-53.

5. Merrett J, Merrett TG. Screening for IgE-mediated allergy. J Clin Immunoassay 1993; 16:164-72.

6. Dekker FW, Muldern JD, Kramps JA, Kaptein AA, Vandenbroucke JP, Dijkman JH. The Phadiatop in vitro test for allergy in general practice: is it useful? Family Practice 1990; 7:144-8.

7. Cantani A, Ferrara M, Barbieri C, Monteleone A, Businco L. Evaluation of a new test (Phadiatop) for screening of respiratory allergic disorders in children. Annals of Allergy 1990; 64:158-61.

8. Lindholm NB, Björneman P. Severity of birch allergy in relation to spec. IgE measured with a new test. New England and Regional Allergy proceedings 1988; 9:422.

9. Zimmerman B, Tremblay D. Atopic burden (specific $\operatorname{lgE}$ ) and severity of allergic disease in children: a clinical evaluation. Allergologie 1989; 12:70.

10. Bengtsson A, Karlsson A, Rolfssen W, Einarsson, R. Detection of allergens in mould and mite preparation by a nitro-cellulose electroblotting technique. Int Arch Allergy Appl Immunol 1986; 80:383-90.

11. Laemmli UK. Cleavage of structural proteins during the assembly of the head of bacteriophage T4. Nature 1970; 227:680.

12. Passing $\mathrm{H}, \mathrm{Bablok} \mathrm{W}$. A new biometrical procedure for testing the equality of measurements from two different analytical methods. J Clin Chem Clin Biochem 1983; 21:709-20.

13. Passing $\mathrm{H}$, Bablok $\mathrm{W}$. Comparison of several regression procedures for method comparison studies and determination of sample sizes. J Clin Chem Clin Biochem 1984; 22:431-45.

14. Passing H, Bablok W, Bender R, Schneider B. A general regression procedure for method transformation. J Clin Chem Clin Biochem 1988; 26:783-90.

15. Altman DG, Bland JM. Measurement in medicine: the analysis of method comparison studies. Statistician 1983; 32:307-17.

16. Nilsson G. Comparison of measurement methods based on a model for the error structure. J Chemometrics 1991; 5:52336.

17. Eriksson NE. Allergy screening with phadiatop and CAP phadiatop in combination with a questionnaire in adults with asthma and rhinitis. Allergy 1990; 45:285-92.

18. Abreu Nogueira JM, Morais de Almerda $M$, Guimaraes Fernandes J, Santa Marta L, Leira Pinto P, Rosado Pinto JE. AlaTOP: sensitivity, specificity and predictive value of a new 'in vitro' screening test of atopy. Allergie et Immunologie 1994; 26:99-101.

19. Matricardi PM, Fattorossi A. Nisini R, Le Moli S, Castagliuolo PD, D'Amelio R. A new screening test for specific IgE to inhalant allergens (phadiatop) in the screening of immediate respiratory hypersensitivity states. Ann Allergy 1989; 63:532-5.

20. Said El Shami A, Alaba O. Liquid-phase in vitro allergen-specific IgE assay with in situ immobilization. Adv Biosci 1989; 74:192-201.

Guido M. P. J. Costongs

Dept. Clinical Chemistry

Maaslandziekenhuis

Walramstraat 23

NL-6131 BK Sittard

The Netherlands 
